\title{
DISCONTINUED ANTI-HYPERTENSIVE MEDICATION: A CASE CONTROL STUDY ON THE STROKE PATIENTS
}

\author{
HOSSAIN MZ ${ }^{1}$, AZAD KAK $^{2}$, HASAN ${ }^{3}$, HUSSAIN T ${ }^{4}$, RAHMAN KM ${ }^{5}$, SALEH MAD ${ }^{6}$, KAHHER MA ${ }^{7}$, \\ AHASAN HAMN ${ }^{8}$, KARIM ME $^{9}$
}

\begin{abstract}
Though it is long known that irregular intake of antihypertensive may cause harm, but still there is much lack of awareness among the patients in this matter. This case controlled study was done in Dhaka Medical College Hospital, Dhaka, to determine the relationship between discontinuation of antihypertensive drugs and the risk of stroke among hypertensive patients. Number of cases was 72. Control group was selected via random sampling of stroke free treated hypertensive group, similar in age to stroke cases. Sampling technique was random systematic sampling. The relationship was determined employing statistical methods including Chi-square $(\chi 2)$ test using computer programs, and significant association between discontinuation of antihypertensive and development of stroke in hypertensive adult patients was found $\chi 2(1, N=103)=32.637, p<0.001$. Odd's ratio is 15.83.
\end{abstract}

Key words: Antihypertensive drugs, stroke patients.

J Dhaka Med Coll. 2013; 22(2) : 173-178.

\section{Introduction}

Stroke and stroke related complications have become so common now-a-days that the word "Stroke" is no longer only a medical term, rather it has gained access to the layman's dictionary. Stroke has been commented to be the most common neurological disease ${ }^{1}$. The burden of the disease is increasing both in our country and globally ${ }^{2,3}$. In Bangladesh, there is no adequate data on incidence and mortality from stroke ${ }^{4}$. The American Health Association estimates that 780000 strokes occur each year; 600,000 of these are new strokes, and 180,000are recurrent strokes ${ }^{5}$. According to yearbook of Department of Medicine at Dhaka Medical College \& Hospital (2012), $14.83 \%$ of total admission was due to stroke. Among them 59.39\% were ischemic stroke, $38.69 \%$ were hemorrhagic stroke \& $1.92 \%$ were undefined $\mathrm{CVD}^{6}$. In a recent Bangladeshi study ${ }^{7}$ shows that $53 \%$ of patients had ischaemic stroke, $40 \%$ intracerebral haemorrhage and only $2 \%$ subarachnoid haemorrhage. $72 \%$ of the patients were male and $28 \%$ were female. The World health Organization has defined stroke as, "Rapidly developing clinical signs of focal (or global) disturbance of cerebral function, with symptoms lasting 24 hours or longer or leading to death, with non-apparent cause other than vascular origin" 8 . Stroke has certain recognized stroke risk factors ${ }^{9}$ among which some are fixed like age, gender, heredity, previous vascular event and high fibrinogen level and some are modifiable like high blood pressure, heart disease (atrial fibrillation, heart failure, endocarditis), diabetes mellitus, hyperlipidemia, smoking, excess alcohol consumption, polycythemia, OCP, social deprivation, etc. Blood pressure is among the most easily and conveniently controllable condition, provided good compliance, awareness and adherence to treatment protocol, and adaptation of a healthy life style. Overall, there

1. Dr. Mohammad Zaid Hossain, Associate Professor, Department of Medicine, Dhaka Medical College \& Hospital, Dhaka.

2. Prof. Khan Abul Kalam Azad, Professor, Department of Medicine, Dhaka Medical College \& Hospital, Dhaka.

3. Dr. Pratyay Hasan, Medical Officer, Department of Medicine, Dhaka Medical College Hospital, Dhaka.

4. Dr. Tahmeed Hussain, Medical Officer, Department of Medicine, Dhaka Medical College Hospital, Dhaka.

5. Dr. Kazi Monisur Rahman, Department of Gastroenterology, Bangabandhu Sheikh Mujib Medical University, Dhaka

6. Dr. Mohammed Abaye Deen Saleh, Registrar, Department of Cardiology, Dhaka Medical College Hospital, Dhaka

7. Prof. Md. Azizul Kahher, Professor of Medicine, Dhaka Medical College Hospital, Dhaka.

8. Prof. HAM Nazmul Ahasan, Professor of Medicine, Dhaka Medical College Hospital, Dhaka.

9. Professor Md. Enamul Karim, Professor of Medicine, Dhaka Medical College Hospital, Dhaka.

Correspondence : Dr. Mohammad Zaid Hossain, Associate Professor, Department of Medicine, Dhaka Medical College \& Hospital, Dhaka. 
is an associationbetween both systolic and diastolic BP and risk of stroke without a clear threshold even at a systolic $\mathrm{BP}$ of $115 \mathrm{~mm} \mathrm{Hg}^{10}$. Meta-analyses of randomized controlled trialshave shown that BP lowering is associated with a $30 \%$ to $40 \%$ reduction in risk of stroke ${ }^{1-13}$. Risk reduction is greater withlarger reductions in $\mathrm{BP}$ without clear evidence of a drugclass-specific treatment effect ${ }^{13}$.Evidence-based recommendations for BP screening and treatment of persons withhypertension are summarized in the American Stroke Association (ASA) Guidelines on the Primary Prevention of Ischemic Stroke $^{14}$ and are detailed in the Seventh Report ofthe Joint National Committee on Prevention, Detection, Evaluation, and Treatment of High Blood Pressure (JNC7) ${ }^{15}$. However, unfortunately, patients do not understand the importance of maintaining regular intake of stroke.A Bangladeshi study ${ }^{16}$ described this condition quite elegantly, where it was shown that $66 \%$ of patients were aware that they were hypertensive though only $12.9 \%$ were taking anti-hypertensive drugs regularly. $62 \%$ of the patients had suffered from stroke within 5 years of detection of hypertension, and $15 \%$ patients died in the hospital. A British study ${ }^{17}$ in 1997 demonstrated that Risk of stroke was clearly related to quality of control of blood pressure with treatment. In routine practice consistent control of blood pressure to below 150/90 mm Hg seems to be required for optimal stroke prevention. In another Bangladeshi study ${ }^{18}, 100$ cases of hypertensive complications due to irregular drug-therapy were studied in medicine units of Dhaka Medical College Hospital, Dhaka, for the period of one year from February 7, 1989 to February 6,1990 . Among those, stroke had headed the list $(48 \%)$ manifesting in various ways e.g. cerebral haemorrhage with focal neurological signs e.g. hemiplegia, hemiperesis, aphasia etc. Hypertension associated with varying degrees of cardiac ischaemias and heart failure was seen in $14 \%$ and $10 \%$ cases respectively. Highest incidence of complications was seen in 1-5 years after detection of hypertension with mean age of $55+/-18.70$ years. The purpose of this case control study is to establish the association between noncompliance of antihypertensive drugs and stroke.

\section{Methods}

It was a case-control study.Study population was selected as follows. The cases were selected ashypertensive patients who sustained a fatal or non-fatal ischaemic or haemorrhagic stroke. Number of cases was 72. Control group was selected viarandom sampling of stroke free treated hypertensive group, health cooperation enrollers; similar in age to stroke cases. Sampling technique was random systematic sampling. Place of study was Dhaka Medical College Hospital, Dhaka. Duration of the study was from January 3, 2013 to June 6, 2013. Method of data collection was done with questionnaire and interviews along with case record forms. For data analysis, Chi square test was employed.

\section{Results}

To look from the angle of discontinuation of drugs, a total of 103 subjects were studied (Table I - Case or control by Frequency of discontinuation of drug Cross tabulation), 72 cases were taken along with 31 controls were selected matching with the case group. Out of 72 cases, $57(79.2 \%)$ discontinued antihypertensive drugs frequently, whereas only $15(20.8 \%)$ discontinued antihypertensive drugs rarely. In contrast with that out of 31 controls, 6 (19.4\%) discontinued antihypertensive drugs frequently and 25 (80.6\%) discontinued antihypertensive drugs rarely. So the case group constituted $90.5 \%$ of the group discontinuing antihypertensive drugs frequently, whereas controls consisted 9.5\%. So 63 patients out of 103 took antihypertensive drugs irregularly which is $61.2 \%$ of the total patients, and only 40 out of $103(38.8 \%)$ took antihypertensive drugs regularly. 
Table-I

Case or control by Frequency of discontinuation of drug Cross tabulation

\begin{tabular}{|c|c|c|c|c|c|}
\hline & & & requency of discon & inuation of drug & Total \\
\hline & & Antih & $\begin{array}{l}\text { dispertensive drug } \\
\text { frequently }\end{array}$ & $\begin{array}{l}\text { Antihypertensive } \\
\text { drug discontinued } \\
\text { rarely }\end{array}$ & \\
\hline Case or & Case & Count & 57 & 15 & 72 \\
\hline control & & $\begin{array}{l}\% \text { within Case or } \\
\text { control }\end{array}$ & $79.2 \%$ & $20.8 \%$ & $100.0 \%$ \\
\hline & & $\begin{array}{l}\% \text { within Frequency } \\
\text { of discontinuation of drug }\end{array}$ & $90.5 \%$ & $37.5 \%$ & $69.9 \%$ \\
\hline & Control & Count & 6 & 25 & 31 \\
\hline & & $\%$ within Case or control & $19.4 \%$ & $80.6 \%$ & $100.0 \%$ \\
\hline & & $\begin{array}{l}\% \text { within Frequency } \\
\text { of discontinuation of drug }\end{array}$ & $9.5 \%$ & $62.5 \%$ & $30.1 \%$ \\
\hline Total & & Count & 63 & 40 & 103 \\
\hline & & $\%$ within Case or control & $61.2 \%$ & $38.8 \%$ & $100.0 \%$ \\
\hline & & $\begin{array}{l}\% \text { within Frequency of } \\
\text { discontinuation of drug }\end{array}$ & $100.0 \%$ & $100.0 \%$ & $100.0 \%$ \\
\hline
\end{tabular}

A Chi square test (Table 2 - Chi Square test for discontinuation of drugs) was performed and from these results there is highly significant association between discontinuation of antihypertensive and development of strokein hypertensive adult patients, $\div 2(1, \mathrm{~N}=103)=32.637, \mathrm{p}<0.001$. Odd's ratio is 15.83 .

Table-II

Chi Square test for discontinuation of drugs

\begin{tabular}{lccccc}
\hline & Value & $\mathrm{df}$ & $\begin{array}{c}\text { Asymp. Sig. } \\
(2 \text {-sided })\end{array}$ & $\begin{array}{c}\text { Exact Sig. } \\
(2 \text {-sided })\end{array}$ & $\begin{array}{c}\text { Exact Sig. } \\
\text { (1-sided) }\end{array}$ \\
\hline Pearson Chi-Square & $32.637^{\mathrm{a}}$ & 1 & .000 & & \\
Continuity Correction ${ }^{\mathrm{b}}$ & 30.167 & 1 & .000 & & \\
Likelihood Ratio $_{\text {Fisher's Exact Test }}$ & 33.456 & 1 & .000 & .000 & .000 \\
Linear-by-Linear Association & 32.320 & 1 & .000 & & \\
N of Valid Cases & 103 & & & & \\
\hline
\end{tabular}

a. 0 cells $(.0 \%)$ have expected count less than 5 . The minimum expected count is 12.04 .

b. Computed only for a $2 \times 2$ table

Among these patients, (Fig. 1. Duration of absence of treatment before development of stroke) $51.6 \%$ of patients developed stroke within 15 daysof discontinuation of drugs, and $16.1 \%$ within 1 month, $18.8 \%$ within 2 month or >than 2 monthof the same. $13.5 \%$ of patients' data were missing.

Among the causes of discontinuation of drugs (Table 3 - Frequency of reason for discontinue Frequencies)were ignorance or lack of awareness $(29.2 \%)$, economical $(25.2 \%)$, asymptomatic $(21.6 \%)$, difficulty in collecting medicine $(15.4 \%)$, others $(8.6 \%)$.

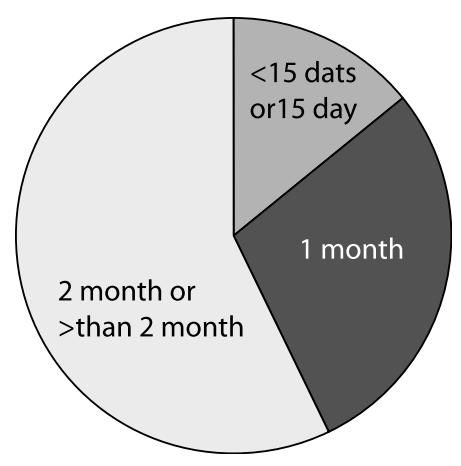

Fig.-1. Duration of absence of treatment before development of stroke 
Table-III

Frequency of reason for discontinue Frequencies

\begin{tabular}{llccc}
\hline & & \multicolumn{2}{c}{ Responses } & Percent \\
& & $\mathrm{N}$ & Percent & of Cases \\
\hline Reasons for discontinue drugs $^{\mathrm{a}}$ & Lack of awareness & 18 & $25.6 \%$ & $29.2 \%$ \\
& Economical & 12 & $19.0 \%$ & $25.2 \%$ \\
& Asymptomatic & 15 & $23.8 \%$ & $21.6 \%$ \\
& Difficulty in collecting medicine & 7 & $11.1 \%$ & $15.4 \%$ \\
& Others & 11 & $17.5 \%$ & $8.6 \%$ \\
\hline Total & & 63 & $100.0 \%$ & $100.0 \%$ \\
\hline
\end{tabular}

a. Group

The incomes of the respondents are shown in the following figures, Fig. 2. Income of the respondents in pie chart:

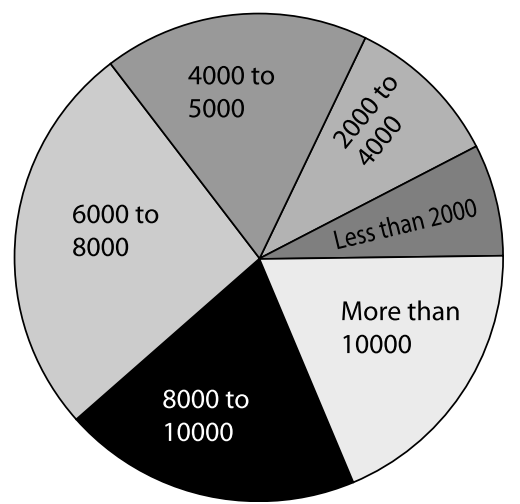

Fig.-2: Income of the respondents in pie chart

\section{Discussion}

A total of 103 subjects were studied (Table I Case or control by Frequency of discontinuation of drug Cross tabulation), 72 cases were taken along with 31 controls were selected matching with the case group. Out of 72 cases, 57 (79.2\%) discontinued antihypertensive drugs frequently, whereas only 15 (20.8\%) discontinued antihypertensive drugs rarely. In contrast with that out of 31 controls, 6 (19.4\%) discontinued antihypertensive drugs frequently and 25 (80.6\%) discontinued antihypertensive drugs rarely. So the case group constituted $90.5 \%$ of the group discontinuing antihypertensive drugs frequently, whereas controls consisted 9.5\%. So 63 patients out of 103 took antihypertensive drugs irregularly which is $61.2 \%$ of the total patients, and only 40 out of $103(38.8 \%)$ took antihypertensive drugs regularly.
A Chi square test (Table-II) was performed and from these results there is highly significant association between discontinuation of antihypertensive and development of strokein hypertensive adult patients, $\div 2(1, \mathrm{~N}=103)=$ $32.637, \mathrm{p}<.001$. Odd's ratio is 15.83 . Hence, it is clearly evident from our study, that discontinuation of antihypertensive increases the risk of stroke greatly, which is similar to the opinion of Mayor (2013) ${ }^{19}$, Du et al. $(1997)^{17}$, etc. According to a population based study by Herttua et al. $(2013)^{20}$. The latter study conducted on the basis of the data collected from the period spanning $1^{\text {st }}$ January 1995 to $31^{\text {st }}$ December 2007 from the Finnish National Register. Of the 73,527 hypertensive patients aged 30 years or older and without pre-existing stroke or cardiovascular disease, 2,144 died from stroke and 24,560 were hospitalized due to stroke during the follow-up. At the 2- and 10-year follow-up after the start of continuous antihypertensive medication, non-adherent patients had 3.81 [95\% confidence interval (CI) 2.85-5.10] and 3.01 (95\% CI: 2.37-3.83) times higher odds of stroke death when compared withthe adherent patients. The corresponding odds ratio (OR) for stroke hospitalization was 2.74 (95\% CI: 2.35-3.20) atYear 2 and 1.71 (95\% CI: $1.49-1.96)$ at Year 10. In the stroke-event year, the ORs were higher, 5.68 (95\% CI: 5.056.39) for stroke death and 1.87 (95\% CI: 1.722.03) for hospitalization. Among those using agents acting on therenin-angiotensin system 
combined with diuretics or-blockers, these ORs were 7.49 (95\% CI: 5.62-9.98) and 3.91(95\% CI: 3.23-4.75), respectively. The associations between non-adherence and stroke followed a dose -response pattern - the poorer the adherence, the greater the risk of death and hospitalization due to stroke. It is also noteworthy that poor control of HTN or nonadherence to antihypertensive medication is considered as an "unrecognized" risk factor in development of cardiovascular disease by many researchers including Munger et al. (2007) ${ }^{21}$.

A Bangladeshi study conducted in $1990^{16}$ showed of the 100 patients studied in Dhaka Medical College Hospital, Dhaka, there were $73(73 \%)$ males, 27 (27\%) patients had no formal schooling and 53 (53\%) had some education. $48(48 \%)$ patients were from middle class and $36(36 \%)$ were poor, 66 (66\%) patients were aware that they were hypertensive though only $8(12.9 \%)$ were taking anti-hypertensive drugs regularly. $62 \%$ of the patients had suffered from stroke within 5 years of detection of hypertension, and $15(15 \%)$ patients died in the hospital.

In our study, the main causes of discontinuation of antihypertensive medication were lack of awareness (28.6\%), financial constraint $(19.0 \%)$, asymptomatic $(23.8 \%)$, difficulty in collecting medicine $(11.1 \%)$ \& others $(17.5 \%)$. A Malaysian study found that non-compliance of antihypertensive medication was significant association low-level of knowledge, low educational level, practices of traditional medicine, dissatisfaction with services by the health staffs, obesity, difficulties in transportation to the clinics and unawareness about their disease ${ }^{22}$. In another study in Congo, five themes emerged as possible explanations for non-compliance: Side effects discouraged patients from taking medication; patients took medication only when they experienced perceived symptoms of hypertension; poor knowledge of the disease and the medication used; lack of support by family members; and difficulty in obtaining antihypertensive medication ${ }^{23}$. Hence, causes of non-compliance found in our study are consistent with other studies.
Though for better compliance it is advised by many researchers to take necessary steps by the physicians such as, patient education, adoption of easy to follow dosage regimen such as once daily regimen ${ }^{24}$, it is found by another study that even an easy regimen like oncedaily schedule may fail to get expected patient compliance $^{25}$ and thus may culminate into poor antihypertensive control.

\section{Conclusion}

There is significant association between discontinuation of antihypertensive medication and the stroke. Much awareness should be raised among both the patients and the physicians. Further study should be conducted to gather further evidence concerning this.

\section{References}

1. Bergen DC. The world-wide burden of neurologic disease. Neurology 1996; 47(1): 21-5.

2. Feigin VL, Lawes CMM, Bennett DA, Anderson CS. Stroke epidemiology: a review of populationbased studies of incidence, prevalence, and casefatality in the late 20th century. Lancet Neurol 2003; 2(1): 43-53.

3. World Health Organization (WHO), Mackay J, Mensah GA. The atlas of heart disease and stroke. Geneva: World Health Organization; 2004.

4. Hossain A, Ahmed N, Rahman M, Islam M, Sadhya G, Fatema K. Analysis of sociodemographic and clinical factors associated with hospitalized stroke patients of Bangladesh. Faridpur Med Coll J 2011; 6(1): 19-23.

5. Rosamond W, Flegal K, Furie K, Go A, Greenlund $\mathrm{K}$, Haase $\mathrm{N}$, et al. Heart disease and stroke statistics-2008 update: a report from the American Heart Association Statistics Committee and Stroke Statistics Subcommittee. Circulation 2008; 117(4): 25-146.

6. Yearbook 2012: Department of Medicine, Dhaka Medical College \& Hospital. Dhaka: Department of Medicine, Dhaka Medical College \& Hospital; 2012 .

7. Siddiqui MR, Islam QT, Iqbal MJ, Binte-Mosharraf SS. Socio-demographic status and associated risk factors of the stroke patients in a a tertiary care hospital of Bangladesh. Anwer Khan Modern Med Coll J 2013; 4(2): 18-22.

8. The World Health Organization MONICA Project (monitoring trends and determinants in cardiovascular disease): a major international 
collaboration. WHO MONICA Project Principal Investigators. J Clin Epidemiol 1988; 41(2): 105-14.

9. Allen C, Lueck C, Dennis M. Neurological Disease. In: Colledge NR, Walker BR, Ralston S, Davidson $\mathrm{S}$, eds. Davidson's principle and practice of medicine. Edinburgh: Elsevier Churchill Livingstone; 2010.

10. Lewington S, Clarke R, Qizilbash N, Peto R, Collins R, Prospective Studies Collaboration. Agespecific relevance of usual blood pressure to vascular mortality: a meta-analysis of individual data for one million adults in 61 prospective studies. Lancet 2002; 360(9349): 1903-13.

11. Lawes CMM, Bennett DA, Feigin VL, Rodgers A. Blood pressure and stroke: an overview of published reviews. Stroke J Cereb Circ 2004; 35(3): 776-85.

12. Yusuf S, Sleight P, Pogue J, Bosch J, Davies R, Dagenais G. Effects of an angiotensin-convertingenzyme inhibitor, ramipril, on cardiovascular events in high-risk patients. The Heart Outcomes Prevention Evaluation Study Investigators. N Engl J Med 2000; 342(3): 145-53.

13. Turnbull F, Blood Pressure Lowering Treatment Trialists' Collaboration. Effects of different bloodpressure-lowering regimens on major cardiovascular events: results of prospectivelydesigned overviews of randomised trials. Lancet 2003; 362(9395): 1527-35.

14. Goldstein LB, Adams R, Alberts MJ, Appel LJ, Brass LM, Bushnell CD, et al. Primary prevention of ischemic stroke: a guideline from the American Heart Association/American Stroke Association Stroke Council: cosponsored by the Atherosclerotic Peripheral Vascular Disease Interdisciplinary Working Group; Cardiovascular Nursing Council; Clinical Cardiology Council; Nutrition, Physical Activity, and Metabolism Council; and the Quality of Care and Outcomes Research Interdisciplinary Working Group: the American Academy of Neurology affirms the value of this guideline. Stroke J Cereb Circ 2006; 37(6): 1583-633.

15. Chobanian AV, Bakris GL, Black HR, Cushman WC, Green LA, Izzo JL, et al. The Seventh Report of the Joint National Committee on Prevention,
Detection, Evaluation, and Treatment of High Blood Pressure: the JNC 7 report. JAMA 2003; 289(19): 2560-72.

16. Roy PK, Arif SM, Alam MR, Khan FD, Ahmad Q, Chowdhury SG. Stroke in patients having inadequate or irregular antihypertensive therapy. Bangladesh Med Res Counc Bull 1990; 16(2): 52-7.

17. Du X, Cruickshank K, McNamee R, Saraee M, Sourbutts J, Summers A, et al. Case-control study of stroke and the quality of hypertension control in north west England. BMJ 1997; 314(7076): 272-6.

18. Chowdhury NA, Hayee MA, Alam N. Study of complications in hypertensive patients having irregular treatment. Bangladesh Med Res Counc Bull 1993; 19(3): 86-93.

19. Mayor S. Non-adherence to medication increases stroke risk in patients with high blood pressure. BMJ 2013; 347: 4586.

20. Herttua K, Tabak AG, Martikainen P, Vahtera J, Kivimaki M. Adherence to antihypertensive therapy prior to the first presentation of stroke in hypertensive adults: population-based study. Eur Heart J 2013; 34(38): 2933-9.

21. Munger MA, Van Tassell BW, LaFleur J. Medication Nonadherence: An Unrecognized Cardiovascular Risk Factor. Medscape Gen Med 2007; 9(3): 58 .

22. Mohd Anuar AR, Shamsul AS. Why hypertensive patients do not comply with their treatment? a case-control study in Perlis, Malaysia. Int Med $\mathrm{J}$ 2012; 19(1): 2 .

23. Fina Lubaki J-P, Mabuza LH, Malete N, Maduna P, Ndimande JV. Reasons for non-compliance among patients with hypertension at Vanga Hospital, Bandundu Province, Democratic Republic of Congo: a qualitative study. Afr J Prim Health Care Fam Med 2009; 1(1): 107-11.

24. Frishman WH. Importance of medication adherence in cardiovascular disease and the value of once-daily treatment regimens. Cardiol Rev 2007; 15(5): 257-63.

25. Vrijens B, Vincze G, Kristanto P, Urquhart J, Burnier M. Adherence to prescribed antihypertensive drug treatments: longitudinal study of electronically compiled dosing histories. BMJ 2008; 336(7653): 1114-7. 